\title{
IMPLIKATUR PERCAKAPAN DALAM NOVEL SIRKUS POHON KARYA ANDREA HIRATA DAN IMPLEMENTASINYA TERHADAP PEMBELAJARAN BAHASA INDONESIA DI SMA
}

\author{
CONVERSATION IMPLICATES IN ANDREA HIRATA'S NOVEL CIRCUS TREE \\ AND ITS IMPLEMENTATION ON INDONESIAN LANGUAGE LEARNING IN \\ HIGH SCHOOL
}

\author{
Gita Amalia; Maria L.A.S; Lita Luthfiyanti \\ Program Studi Pendidikan Bahasa dan Sastra Indonesia \\ FKIP Universitas Lambung Mangkurat \\ gitaamallia25@gmail.com
}

\begin{abstract}
Abstrak
Penelitian ini menguraikan implikatur percakapan pada novel Sirkus Pohon dan akan diimplementasikan pada pembelajaran bahasa Indonesia di SMA. Metode yang dipakai yaitu metode penelitian deskriptif dengan jenis penelitian kualitatif. Setelah melihat hasil analisis data pada novel Sirkus Pohon karya Andrea Hirata, terdapat 20 buah implikatur percakapan dengan 12 tujuan dari berimplikatur, yaitu: 1) memberikan sindiran; 2) memberikan persetujuan; 3) memberikan penegasan; 4) menyatakan permintaan; 5) memenuhi permintaan; 6) memberikan persyaratan; 7) memberikan penghormatan; 8) melakukan penolakan; 9) menyatakan rasa tidak percaya; 10) memberikan perintah; 11) memberikan peringatan; 12) membela diri. Pembelajaran bahasa Indonesia untuk tingkat SMA yang berhubungan dengan implikatur bisa diaplkasikan dalam memahami materi pembelajaran berupa sebuah teks. Aplikasinya ketika peserta didik mendapatkan sebuah teks, berupa teks anekdot, teks cerita (novel) sejarah, maupun sebuah buku fiksi, peserta didik mampu memahami teks tersebut secara tepat. Peserta didik dapat memahami makna yang ambigu, dan mendapatkan pesan yang tersirat dalam materi tersebut. Dengan demikian materi pembelajaran dapat dipahami dan tujuan pembelajaran tercapai.

Kata kunci: implikatur percakapan, novel, pembelajaran bahasa Indonesia
\end{abstract}

\section{Abstract}

This research outlines the conversation's implications in Andrea Hirata's Circus tree and will be implemented on Indonesian language learning in high school. This study uses descriptive research methods with qualitative research types. Based on the results of data analysis on the novel Circus Tree by Andrea Hirata, there are 20 pieces of conversation with 12 objectives of a set, namely: 1) giving innustants; 2) give consent; 3) Provide affirmations; 4) Declare the request; 5) fulfill the request; 6) provide the requirements; 7) Pay homage; 8) Commit rejection; 9) expressed a sense of disbelief; 10) give orders; 11) Give warning; 12) defend themselves. Indonesian language learning for high school level related to Implikature can be applied in understanding leaming material in the form of text. The application when learners get a text, anecdotal text, a historical story text, or a fiction book, learners are able to understand the text appropriately. Learners can understand the ambiguous meaning, and get the message implied in the material. Thus learning materials can be understood and leaming objectives are achieved.

Keywords: conversational implicature, novel, Indonesian languange learning 


\section{Pendahuluan}

Bahasa penting dalam kehidupan seharihari, terdapat banyak fungsi dalam bahasa, diantaranya dapat berguna sebagai alat komunikasi melakukan tanya jawab dan memberikan informasi kepada banyak orang. Dalam berinteraksi antarsesama tidak jarang informasi yang disampaikan memiliki makna yang tersirat. Untuk memahami hal tersebut yaitu dengan ilmu pragmatik yang memaparkan mengenai implikatur.

Pragmatik merupakan kajian terhadap makna penutur. Banyak hal yang tidak dikatakan oleh penutur dapat diketahui sebagai bagian dari apa yang dikomunikasikan. Lebih jelasnya, di dalam pragmatik terdapat konsep yang paling menonjol, yakni implikatur.

Pada implikatur, hubungan antara apa yang dituturkan oleh penutur dengan makna sebenarnya itu bersifat tidak mutlak. Komunikasi yang berjala lancar antara penutur dengan lawan bicaranya terjadi karena mereka memiliki pengetahuan yang sama tentang sesuatu yang dipertuturkan. Dengan demikian, dalam percakapan tidak jarang mengandung implikatur didalamnya, sehingga peneliti menganggap implikatur sebagai suatu hal yang menarik untuk diteliti karena implikatur adalah tuturan yang memiliki makna tersirat yang berbeda dari apa yang disampaikannya, tetapi dalam keadaan tersebut komunikasi tetap berjalan dengan lancar tanpa ada kesulitan untuk penutur dan lawan tutur menafsirkan maknanya.

Percakapan yang mengandung implikatur tidak selalu terjadi saat percakapan secara Iangsung saja, karena juga biasa ditemukan dalam kutipan sebuah novel. Novel merupakan bentuk karya sastra yang didalamnya terdapat banyak percakapan.

Bentuk karya sastra buku berjenis novel ini sangat banyak digemari masyarakat karena isinya yang menarik dan imajinatif. Sekarang, banyak novel yang dijadikan film, ditayangkan ditelevisi, diperankan oleh bintang-bintang film yang memiliki nama besar. HaI itu membuat novel memiliki kualitas yang sangat dipertanggungjawabkan.

Tidak semua kalimat dalam novel maknanya disampaikan secara langsung dan tidak semua percakapan antartokoh maknanya terdengar sesuai dengan apa yang dipertuturkan. Iniah mengapa dirasa perlu bagi peneiti untuk 
melakukan penelitian mengenai implikatur yang terdapat pada novel.

Pada penelitian ini novel yang digunakan adalah novel Sirkus Pohon yang dibuat oleh Andrea Hirata. Peneliti memilih menggunakan novel tersebut sebagi objek penelitian karena pemanfaatan konteks berimplikatur banyak digunakan di peristiwa tutur dalam novel ini. Peneliti tertarik dengan tuturan tokoh-tokoh dalam cerita yang menceritakan kehidupan sehari-hari masyarakat saat berinteraksi antarsesama, mengenai percintaan, mengenai keluarga, serta ditambah konflik lainnya.

Segala sesuatu yang dijadikan sebagai materi ketika pelajaran berlangsung tentunya memiliki kegunaan yang sesuai dengan tujuan pembelajaran. Berdasarkan uraian tersebut, peneliti mengangkat juduI "Implikatur Percakapan Dalam Novel Sirkus Pohon Karya Andrea Hirata dan Implementasinya Terhadap Pembelajaran Bahasa Indonesia di SMA".

Singgah (2018) juga melakukan penelitian dengan judul "Implikatur pada Ungkapan di Badan Angkutan Umum Wilayah Tanjung Karang dan Implikasinya". Hasil peneIitian tersebut, yaitu dalam penelitian ini masyarakat dirasa perlu mengerti mengenai implikatur ungkapan yang ada pada badan angkutan umum.

Perbedaan penelitian ini dengan penelitian terdahulu, yaitu dalam penelitian ini peneliti tidak memaparkan pelanggaran prinsp kerja sama, tetapi penelitian ini mencoba memaparkan implikatur percakapan pada nove Sirkus Pohon karya Andrea Hirata serta makna tuturan dalam berimpikatur. Penelitian ini menjelaskan maksud yang ingin disampaikan penutur ketika berimplikatur saat melakukan percakapan. Selanjutnya, penelitian implikatur percakapan dalam novel karangan Andrea Hirata yang memiliki judul Sirkus Pohon ini juga diimplementasikan terhadap pembelajaran bahasa Indonesia di SMA.

\section{Metode Penelitian}

\section{Jenis Penelitian}

Penelitian ini memiliki jenis penelitian kualitatif. Desain penelitian yang digunakan adalah metode deskriptif kualitatif.

\section{Sumber Data dan Data}

Sumber data yang digunakan pada penelitian ini berupa novel Sirkus Pohon karya Andrea Hirata yang diterbitkan oleh PT Bentang Pustaka 
cetakan keempat pada Mei 2018, yang terdiri dari 87 bab dengan tebal buku 410 halaman. Data dalam penelitian ini adalah kalimat-kalimat yang mengandung implikatur dari novel Sirkus Pohon karya Andrea Hirata berupa percapakan antartokoh.

\section{Teknik Pengumpulan Data}

Dalam penelitian ini peneliti mendapatkan pemerolehan data melalui sumber tertulis. Peneliti membaca, menandai, dan mengindentifikasi percakapan yang terdapat pada novel Sirkus Pohon karya Andrea Hirata yang termasuk dalam implikatur percakapan, kegiatan yang dilakukan penulis saat mengnalisis data adalah sebagai berikut.

1. Membaca novel Sirkus Pohon secara keseluruhan dengan cermat.

2. Memilah-milah percakapan dalam novel yang dijadikan sebagai objek penelitian dalam penelitian ini.

3. Mengidentifikasi data yang terdapat dalam novel Sirkus Pohon tersebut yaitu yang mengandung implikatur percakapan.

\section{Teknik Analisis Data}

Teknik analisis isi merupakan teknik analisis data yang dilakukan peneliti saat melakukan penelitian ini. Teknik analisis ini dilakukan setelah data terkumpul yang kemudian dilakukan pendeskripsian secara objektif, sistematis, dan kualitatif. Rangkaian kegiatan dalam melakukan analisis data ini adalah sebagai berikut.

1. Melakukan analisis setiap percakapan yang termasuk dalam implikatur percakapan.

2. Mendeskripsikan implikatur yang melatarbelakangi percakapan dan analisis maknanya.

3. Mendeskripsikan hasil analisis implikatur percakapan yang diimplementasikan dalam pembelajaran bahasa Indonesia di SMA.

\section{Hasil Penelitian dan Pembahasan}

Berdasarkan penelitian yang telah dilakukan pada novel Sirkus Pohon karya Andrea Hirata, ditemukan 20 data hasil bacaan berdasarkan rumusan masalah yang pertama, yaitu mengenai implikatur percakapan dalam novel.

\section{1) Data 1}

Azizah : Jangan kerja karena
belas kasihan orang!
Lelaki itu harus bekerja
tetap! Harus punya
pekerjaan tetap yang
berwibawa! Lelaki itu
bekerja di kantor desa,
di pemda, di toko, di
rumah sakit, di restoran,


di pabrik, di kapal, di

PN Timah, di kantor

Syahbandar. Ada jam

kerjanya, ada tas

kerjanya.

(Azizah terus membentak, sambil mengingat-ingat apa yang ingin dikatakannya)

Azizah : Gajinya tetap per bulan, ada THR-nya, ada lemburnya, ada perjalanan dinasnya, ada rapat-rapatnya, ada naik pangkatnya, ada naik gajinya, ada tunjangannya, serta ada cutinya.

Sobri : Tengoklah Zah, dimana-mana, jika ada tulisan "Ada lowongan" selalu ada balasan pantun tak berirama di bawahnya, "SMA atau sederajat".

(Sumber data, Hirata, 2018:11-

\section{P1 : Azizah \\ P2 : Sobri}

Implikatur yang terdapat pada percakapan tersebut ada pada ujaran P1, yaitu "Jangan kerja karena belas kasihan orang! Lelaki itu harus bekerja tetap! Harus punya pekerjaan tetap yang berwibawa! Lelaki itu bekerja di kantor desa, di pemda, di toko, di rumah sakit, di restoran, di pabrik, di kapal, di PN Timah, di kantor Syahbandar. Ada jam kerjanya, ada tas kerjanya, ada seragamnya, ada pulpen di sakunya!" Melalui ujarannya tersebut P1 memiliki maksud menyindir pekerjaan P2 yang bekerja serabutan di pasar, yaitu kadang sebagai kuli angkut, pekerjaan tersebut hanya menerima imbalan sesuai pemberian orang. Selain itu implikatur percakapan juga terdapat pada ujaran P2, yaitu "Tengoklah Zah, dimana-mana, jika ada tulisan "Ada lowongan" selalu ada balasan pantun tak berirama di bawahnya, "SMA atau sederajat". Melalui ujaran tersebut P1 mengimplikasikan makna bahwa dia tidak memiliki kemampuan untuk bekerja sesuai kriteria yang disebutkan P1, hal itu karena pendidikannya yang hanya lulusan SD. 
Implikatur: P1 memberikan sindiran kepada P2.

\section{2) Data 2}

Taripol: Takkan melesat! Semua orang seberang kenal Soridin Kebul.

Sobri : Ojeh, Bos.

Taripol: Jangan lupa ambil uang darinya.

Sobri : Delapan enam, Bos!

Sobri : Ojeh! Ojeh! Ojeh! Bos! (dengan polos sambil tersenyum lebar)

(Sumber data, Hirata, 2018:30)

P1 : Taripol

P2 : Sobri

Percakapan antara P1 dan $\mathrm{P} 2$ tersebut mengenai pemberian tugas dari P1 kepada P2 untuk mengantarkan sebuah corong toa. Implikatur yang terdapat pada percakapan tersebut ada pada ujaran P2, yaitu "Delapan enam, Bos". Kalimat tersebut merupakan implikatur percakapan yang menyetujui bahwa P2 memastikan akan menjalankan tepat sesuai perintah P1. Selain itu juga terdapat implikatur percakapan dengan maksud menegaskan pada ujaran P1, yaitu "Jangan lupa ambil uang darinya". Setelah itu "Sudah itu kita pelesiran ke Belantik nonton pelem Stepan Segel". Pada ujaran pertama P2 sudah menyetujui perintah $\mathrm{P} 1$, tetapi P2 menegaskan lagi dengan ujaran kedua. Pada ujaran kedua terdapat kalimat "Sudah itu...." yang bermaksud bahwa setelah P2 menjalankan perintahnya barulah menonton.

Implikatur: P2 menyetujui permintaan P1 dan P1 memberikan penegasan kepada $\mathrm{P} 2$.

Dalam penelitian ini, terdapat banyak penggunaan implikatur percakapan. Novel Sirkus Pohon yang merupakan karya seorang penulis ternama Andrea Hirata ini banyak menghadirkan sindiran sosial di dalamnya. Hal ini tidak disampaikan penulis secara langsung, tetapi diselipkan pada ujaran di setiap percakapan tokohnya. Penulis, ingin menampilkan banyaknya pengangguran yang ada di karenakan pendidikan yang kurang. Syarat seorang pelamar 
kerja adalah SMA sederajat, hal itu sangat banyak dibahas dalam novel ini. Selain itu, penulis juga memberikan sindiran sosial bahwa banyak wanita yang ingin memiliki suami berpenghasilan tetap, hal itu tidak dihadirkan secara langsung, akan tetapi melalui omelan-omelan adik dari Sobri yang merupakan tokoh dalam novel tersebut.

Berdasarkan penjelasan di atas dan hasil penelitian ini, implikatur percakapan banyak terjadi di lingkungan sekitar kita, yaitu pada beberapa acara televisi, dalam kehidupan sehari-hari, dan juga pada sebuah karya sastra berbentuk prosa seperti novel.

\section{Implementasi terhadap Pembelajaran}

\section{Bahasa Indonesia di SMA}

Penggunaan implikatur yakni untuk menyampaikan maksud yang tersirat pada setiap ujaran yang disampaikan ketika melakukan pembicaraan. Implikatur percakapan yang terdapat pada objek penelitian yaitu berupa novel Sirkus Pohon yang ditulis Andrea Hirata ini dapat diimplementasikan pada pembelajaran bahasa Indonesia di SMA, yaitu dalam aspek memahami sebuah teks. Hasil penelitian implikatur percakapan ini dapat diimplementasikan di SMA pada beberapa materi. Pada materi teks anekdot, terdapat pada kelas $\mathrm{X}$, yaitu KD 3.5 Menilai isi dan aspek makna tersirat dalam teks anekdot. Selanjutnya terdapat materi buku fiksi dan nonfiksi, terdapat pada kelas XII, yaitu KD 3.11 Menganalisis pesan dari satu buku fiksi yang dibaca. Pada materi teks cerita (novel) sejarah, terdapat pada kelas XII, yaitu KD 3.9 Menganalisis kebahasaan teks cerita (novel) sejarah dan menjelaskan makna kias yang terdapat dalam teks cerita (novel) sejarah. Pada sebuah materi pembelajaran tidak jarang ditemukan kalimat yang bermakna ambigu. Pemahaman mengenai implikatur ini, diharapkan menghindari keambiguan makna yang dipahami peserta didik. Bagi pendidik, pemahaman mengenai implikatur ini dapat berpengaruh terhadap hasil pemahaman peserta didik mengenai materi yang didapatkan peserta didik berupa sebuah teks, memahami makna yang tersirat didalamnya, serta memahami pertanyaan mengenai materi tersebut. Dengan demikian peserta didik mampu mendapatkan pembelajaran yang efektif, baik secara individu maupun 


\author{
secara berkelompok ketika \\ pembelajaran bahasa Indonesia \\ berlangsung.
}

\section{Simpulan dan Saran}

\section{Simpulan}

Implikatur percakapan yang ditemukan yaitu terdapat 20 buah implikatur percakapan dengan 12 tujuan dari berimplikatur, yaitu: memberikan sindiran; 2) memberikan persetujuan; 3) memberikan penegasan; 4) menyatakan permintaan; 5) memenuhi permintaan; 6) memberikan persyaratan; 7) memberikan penghormatan; 8) melakukan penolakan; 9) menyatakan rasa tidak percaya; 10) memberikan perintah; 11) memberikan peringatan; 12) membela diri.

Implikatur percakapan yang terdapat dalam novel karangan dari Andrea Hirata tersebut dapat diimplementasikan pada pembelajaranu bahasa Indonesia di SMA, yaitu dalam aspek memahami sebuah teks. Pada pembelajaran bahasa Indonesia, peserta didik dituntut untuk memahami sebuah materi pada saat pembelajaran berlangsung. Peserta didik diharapkan mampu mengevaluasi isi maupun makna tersirat yang terdapat dalam sebuah teks. Sebagai seorang pendidik, pengetahuan tentang implikatur percakapan dapat membantu pendidik mengajarkan kepada peserta didik untuk dapat memahami sebuah teks agar bersesuaian dengan bahan ajar sehingga tujuan pembelajaran yang telah dibuat diharapkan tercapai. Aplikasinya yaitu pada materi teks anekdot yang terdapat pada kelas X, yaitu KD 3.5 Menilai isi dan aspek makna tersirat dalam teks anekdot. Selanjutnya pada materi membaca buku fiksi dan nonfiksi yang terdapat pada kelas XII, yaitu KD 3.11 Menganalisis pesan dari satu buku fiksi yang dibaca. Pada materi teks cerita (novel) sejarah yang terdapat pada kelas XII implikatur juga dapat diaplikasikan, yaitu KD 3.9 Menganalisis kebahasaan teks cerita (novel) sejarah dan menjelaskan makna kias yang terdapat dalam teks cerita (novel)sejarah.

\section{Saran}

1. Bagi pembaca, penelitian tentang implikatur percakapan dalam novel Sirkus Pohon karya Andrea Hirata ini diharapkan mampu menambah wawasan tentang implikatur, khususnya implikatur percakapan.

2. Bagi pendidik pada sekolah menengah atas dapat menggunakan penelitian mengenai implikatur percakapan dalam novel Sirkus 
Pohon karya Andrea Hirata sebagai referensi dalam menyampaikan bahan ajar agar peserta didik mampu mengemukakan pendapat dengan alasan yang logis serta kalimat yang baik dan benar dalam kegiatan pembelajaran. Keefektifan suatu komunikasi tercipta ketika penutur dan lawan tutur mampu memahami sebuah tuturan.

3. Bagi peneliti yang berminat pada bidang implikatur percakapan agar dapat melakukan penelitian menggunakan sumber data yang berbeda. Selain itu juga bagi peneliti selanjutnya agar melakukan penelitian mengenai kajian pragmatik yang lain dalam novel yang dibuat oleh Andrea Hirata yang berjudul Sirkus Pohon.

\section{Daftar Pustaka}

\section{Dari Buku Teks}

Abdul Chaer. 2006. Tata Bahasa Praktis Bahasa Indonesia. Jakarta: PT Rineka Cipta.

Arifin, Bustanul dan Abdul Rani. 2000. Prinsip-Prinsip Analisis Wacana. Jakarta: Departemen Pendidikan Nasional.

Ghony, M Djunaidi dan Fauzan Almanshur. 2016. Metode Penelitian Kualitatif. Yogyakarta: Ar-Ruzz Media.

Humaidi, Akhmad. 2008. Bahasa Indonesia untuk Penulisan
Karya Ilmiah. Banjarbaru: Scripta Cendikia.

Jumadi. 2006. Pragmatik. Banjarmasin: PBS FKIP Universitas Lambung Mangkurat.

Mulyana. 2005. Kajian Wacana: Teori, Metode, dan Aplikasi PrinsipPrinsip Analisis Wacana. Yogyakarta: Tiara Wacana.

Nababan, P.W.J. 1987. Ilmu Pragmatik: Teori dan Penerapannya. Jakarta: Departemen Pendidikan dan Kebudayaan.

Purba, Antilan. 2010. Sastra Indonesia Kontemporer. Yogyakarta: Graha Ilmu.

Putrayasa, Ida Bagus. 2014. Pragmatik. Yogyakarta: Graha Ilmu.

Rahardi, Kunjana. 2005. Pragmatik: Kesantunan Imperatif Bahasa Indonesia. Jakarta: Erlangga.

Wicaksono, Andi. 2014. Pengkajian Prosa Fiksi. Yogyakarta: Penerbit Garudhawaca.

\section{Dari Jurnal}

Akib, Haedar. 2010. Implementasi Kebijakan: Apa, Mengapa, Dan Bagaimana. Jurnal Administrasi Publik, (pdf), Vol. 1 No. 1, (diakses 21 Januari 2020).

Choirudin, M. Mahfud. Siti Samhati., dan Iing Sunarti. 2018. Implikatur Percakapan Kumpulan Cerpen Filosofi Kopi dan Implikasinya Terhadap Pembelajaran Bahasa Indonesia. Jurnal Kata (Bahasa, Sastra, dan Pembelajarannya), (pdf), 
Vol. 6 No. 1, (diakses 8 Februari 2020).

Hilaliyah, Hilda dan Awaludin. 2016. Implikatur Percakapan Pada Novel Taheran Dalam Toples Karya Aminatul Faiziah. Deiksis, (pdf), Vol. 08 No. 01, (diakses 18 Januari 2020).

Kurnia, Santi. Zainal Rafli., dan Miftahulkhairah Anwar. 2019. Implikatur Pecakapan dalam Gelar Wicara Indonesia Lawak Klub. Deiksis, (pdf), Vol. 11 No. 3, (diakses 8 Februari 2020).

Marini, Yosefina Eva. Mulyanto Widodo., dan Eka Sofia Agustina. 2017. Implikatur pada Ungkapan di Badan Angkutan Umum Wilayah Tanjung Karang dan Implikasinya. Jurnal Kata (Bahasa, Sastra, dan Pembelajarannya), (pdf), Vol. 5 No. 2, (diakses 18 Januari 2020).

Saputra, Mujiyono Wiryotinoyo, Akhyarudin. 2015. Implikatur Percakapan dalam Stand Up Comedy Indonesia di Stasiun Kompas TV Edisi April 2014. Jurnal Pendidikan Bahasa dan Sastra, (pdf), Vol. 4 No. 2, (diakses 8 Februari 2020).

Sulistyowati. 2013. Pelanggaran Prinsip Kerja Sama Dan Implikatur Percakapan Dalam Film Petualangan Sherina Karya Riri Riza. Skriptorium, (pdf), Vol. 2 No. 2, (diakses 18 Januari 2020). 